\title{
DATA ANALYSIS AND CALIBRATION OF RADIOCARBON DATING RESULTS FROM THE CEMETERY OF THE MARQUISES OF JIN
}

\author{
Xiangyang $\mathrm{Lu}^{1,2} \cdot$ Zhiyu Guo $^{1} \cdot$ Hongji $\mathrm{Ma}^{1} \cdot{\text { Sixun } \text { Yuan }^{3}} \cdot$ Xiaohong $\mathrm{Wu}^{3}$ \\ ABSTRACT. The chronology study of the cemetery of Marquises of Jin is valuable to improving the chronological table of \\ Marquis of Jin family. It is also helpful for improving the chronological table of the Zhou Dynasty. The samples were mea- \\ sured at Peking University (PKUAMS). We also made an interlaboratory check with Isotrace to ensure the accuracy. By care- \\ ful analysis of archaeological information, we built different models and calibrated by OxCal. The calibration results, both \\ sampling contexts and estimations, are in very good agreement with the historical record. Because the dates of some events \\ correspond to the special part of the curve, the calibration gets very high precision. The calibration result of tomb M93 sug- \\ gests that its host is Marquis Shangshu instead of Marquis Wen.
}

\section{INTRODUCTION}

Jin was one of the vassal states of the Zhou Dynasty. The cemetery of the Marquises of Jin is located at Tianma-Qucun in the Shanxi Province. Eight marquis mausoleums and several related tombs were excavated. Based on archaeological studies show that those mausoleums belonged to the third to the tenth (or eleventh) marquiess for seven (or eight) generations. Those marquises lived from the early-middle Western Zhou Dynasty to the early Eastern Zhou Dynasty (Archaeology Department 1995). In the chronological table of the Zhou Dynasty in Shi Ji, the part prior to $841 \mathrm{BC}$ is not given. For Jin, the chronological table of the family is in a similar state. This is an opportunity for radiocarbon to help to improve the table.

For the project "Xia-Shang-Zhou Chronology", Peking University (PKUAMS) measured samples from five of the eight marquises and the related tombs. The original sample material is charcoal and bone. To figure out which component of bone is better for ${ }^{14} \mathrm{C}$ dating, we pretreated some bone by gelatin-extraction and some by the amino-acid method (Wu et al. 2000). Because the upgrade of the PKUAMS system was just finished when we measured those samples, we also sent two pretreated samples to the Isotrace Laboratory in Toronto, Canada, for interlaboratory checking. The checking result of both laboratories shows good agreement.

Some of the results (Wu et al. 2000) were presented at the most recent accelerator mass spectrometry conference (AMS-8) in Vienna. At that time, we had only limited experience with the application of OxCal. We took a conservative model for the calibration, and only 10 dates were used. The calibration results agree with the archaeologists suggestion. In this paper, we try to improve the calibration model to get higher precision. We also replenished a few new data in the calibration.

\section{Archaeological Information}

There are 17 tombs with some sacrificial pits in the Jin Marquises' cemetery, which is divided into eight groups respective to eight marquises and their wives. From the historical record and archaeological study, those tombs have the following relationship as shown in Table 1.

Most of the hosts have been identified by archaeologists, except the host of M93. Some believe that the host of M93 is Marquis Wen, but others believe that the host is his uncle Shang. Those events offer

\footnotetext{
${ }^{1}$ Institute of Heavy Ion Physics and MOE Key Laboratory of Heavy Ion Physics, Peking University, Beijing 100871, P. R. China

${ }^{2}$ Corresponding author. E-mail: xylu@ihipms.ihip.pku.edu.cn.

${ }^{3}$ Department of Archaeology, Peking University, Beijing 100871, P. R. China
} 
a continual time sequence. The taphonomy of the unearthed artifacts shows that those tombs covered the period from early Western Zhou to early Eastern Zhou. The beginning of Eastern Zhou is 770 BC.

The tombs at locations M11 and M87 are sacrificial pits. M11 broke through the south passage of M8. M87 broke through the south passage of M64. Except for horse bone, there were no other remains in the sacrificial pits.

When the cemetery was unearthed, archaeologists found that many tombs had been disturbed. Therefore, they collected samples from only five groups of tombs.

Table 1 Relationship of Marquises of Jin and the tombs in the cemetery

\begin{tabular}{|c|c|c|c|c|}
\hline \multirow[b]{2}{*}{$\begin{array}{l}\text { Marquis } \\
\text { name }\end{array}$} & \multicolumn{3}{|c|}{ Tomb code } & \multirow[b]{2}{*}{$\begin{array}{l}\text { Pit code } \\
\text { (sacrificial } \\
\text { remains) }\end{array}$} \\
\hline & Marquis & $\begin{array}{l}\text { Marquis's } \\
\text { wife }\end{array}$ & $\begin{array}{l}\text { Human } \\
\text { buried alive }\end{array}$ & \\
\hline $\mathrm{Wu}$ & M9a & M13 & & \\
\hline Cheng & M6 & M7 & & \\
\hline $\mathrm{Li}$ & M33 & M32 & M108 & \\
\hline Jing & M91 & M92 & & \\
\hline Lii & M1 & M2 & & \\
\hline Xian & M8 $8^{\mathrm{a}}$ & M31 & M39a & M11 ${ }^{\mathrm{a}}$ \\
\hline $\mathrm{Mu}$ & M64 ${ }^{\mathrm{a}}$ & M62 & M63 & M87a \\
\hline Wen & M93 $^{\mathrm{a}}$ & M102 & & M93 ${ }^{a}$ (Pit 27) \\
\hline
\end{tabular}

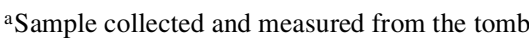

\section{METHOD}

\section{Sample Collection, Preparation, and Measurement}

Three kinds of samples were available for ${ }^{14} \mathrm{C}$ dating. They were bone (human and animal), charcoal, and wood. The wood samples were usually from a coffin. Such a sample probably had a very long lifetime, so it is difficult to know its age at the time of use. However, bone is good for ${ }^{14} \mathrm{C}$ dating; from some tombs, archaeologists found marquises bones that directly related with the marquises death dates. The animal bone is from horses found in some sacrificial pits. The bone is related to memorial ceremonies that may have been held at a time very close to the burial. For other tomb groups, because of distribution, archaeologists can only offer a charcoal sample. All of the charcoals were prepared from small tree branches. The average diameter of each carbonated branch was about $1 \mathrm{~cm}$. That means the material did not live very long. The charcoals were put between the tomb pit and coffin to keep the environment dry. This means they could not be prepared much earlier than the burial. Therefore, the charcoal is a better sample material than the coffin planking. For the above reasons, we chose bone and charcoal samples for ${ }^{14} \mathrm{C}$ dating.

All the samples were prepared at the laboratory of the Department of Archaeology, Peking University (Wu et al. 1999) and measured at the AMS laboratory at the Institute of Heavy Ion Physics, Peking University (PKUAMS). The samplepreparation details have been described previously (Wu et al. 2000; Guo et al. 2000). To check the reproduction of sample preparation for samples SA98094 and SA98096, we arranged the preparation twice, which was distinguished by the extension codes "- 1 " and "-2". To determine which component from bone was better for ${ }^{14} \mathrm{C}$ dating, those bones were pretreated by both gelatin-extraction and the amino-acid method. The latter was marked with an extra code "A". Table 2 shows the measurement results as well as the data from ISOTRACE. 


\section{Calibration}

Using Bayesian statistics is a good approach to reduce the uncertainty range of the calibration results for those data that have some relation. The OxCal program (Bronk Ramsey 1995, 1999, 2000) was used to convert the ${ }^{14} \mathrm{C}$ ages to calendar ages. Following the program definitions, data have been arranged in different phases. Because no "overlap" occurred in our study, we use "BOUNDARY" (Buck et al. 1992) to separate the phases for higher calibration precision. The beginning and end of the data sequence are also restricted by boundaries. OxCal 3.5 and INTCAL98 (Stuiver et al. 1998) have been used for the calibration. The following is our calibration model (Model A):
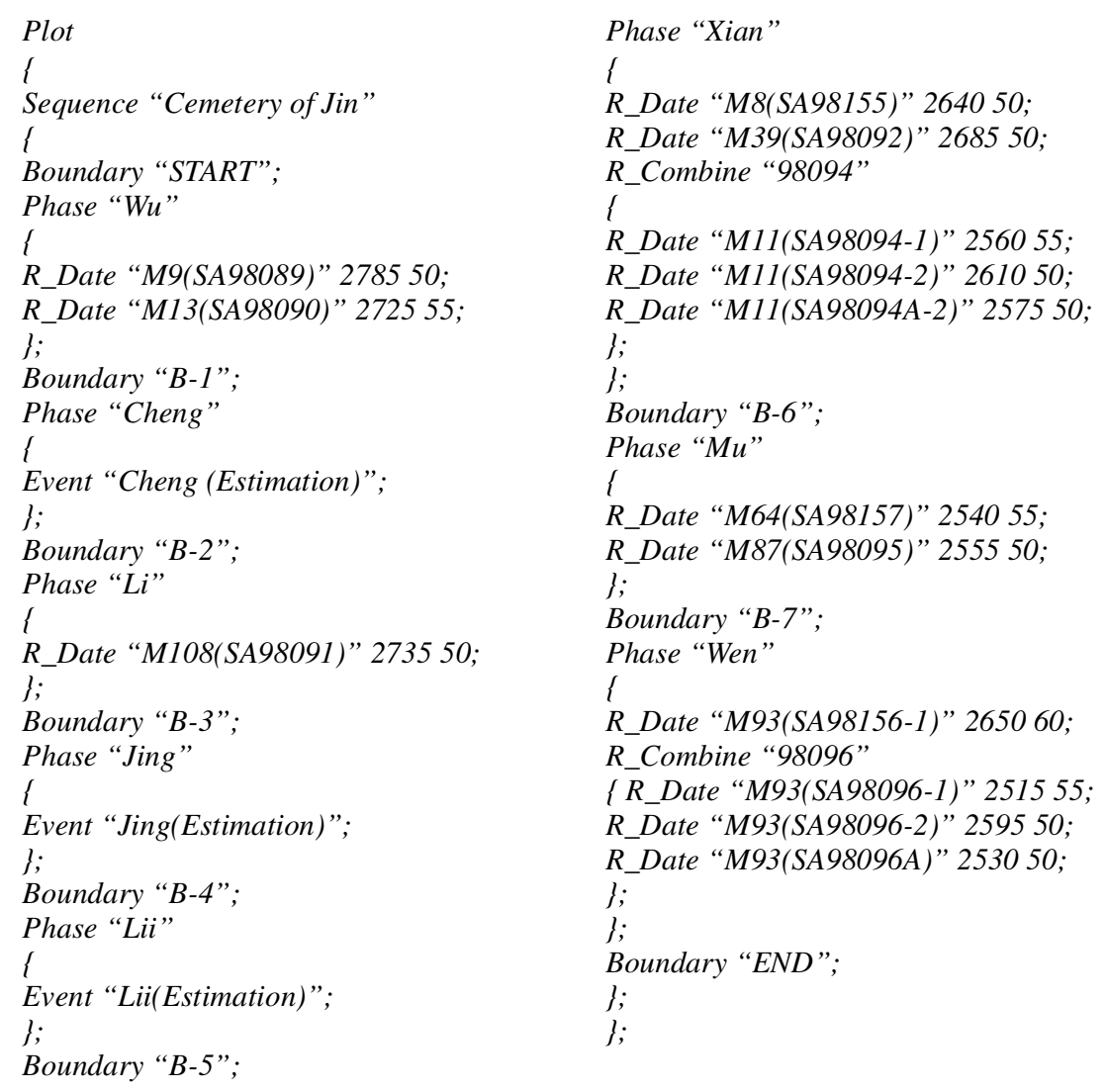

Table 3 shows the calibration result. In this model, although we know that the sacrificial pits M11 are not earlier than tomb M8, and M87 is not earlier than M64, we do not know the time gap. It is possible that the memorial ceremonies were held very close to the time when the Marquises died. For this reason, we set the data with the Marquises in the same phase.

In the calibration, we use the "R_Combine" function to combine the data of the samples SA98094 and SA98096, because those data are from the same origin. The combination also can provide a more reliable result and higher precision. We do not combine the data of SA98157 with SA99043. Although those two samples are from M64, one is charcoal and the other is human bone. Their carbon origins are different. 
Table $2{ }^{14} \mathrm{C}$ results from the cemetery of the Marquises of Jin

\begin{tabular}{llllrc}
\hline Marquise & Tomb & Material & Lab code & $\begin{array}{c}\delta^{13} \mathrm{C} \\
(\%)\end{array}$ & $\begin{array}{c}{ }^{14} \mathrm{C} \text { age } \\
(\mathrm{BP})\end{array}$ \\
\hline Wu & M9 & Human bone & SA98089 & -12.77 & $2785 \pm 50$ \\
& M13 & Human bone & SA98090 & -8.36 & $2725 \pm 55$ \\
Li & M108 & Human bone & SA98091 & -7.93 & $2735 \pm 50$ \\
Xian & M8 & Charcoal & SA98155 & -25.13 & $2640 \pm 50$ \\
& & & TO-7998 & & $2630 \pm 40$ \\
& M39 & Human bone & SA98092 & -7.38 & $2685 \pm 50$ \\
& M11 & Horse bone & SA98094-1 & -13.18 & $2560 \pm 55$ \\
& & & SA98094-2 & -12.77 & $2610 \pm 50$ \\
& & & TO-7999 & & $2570 \pm 50$ \\
Mu & M64 & Human bone & SA99994A & -12.29 & $2575 \pm 50$ \\
& M64 & Charcoal & SA98157 & -10.07 & $2670 \pm 40$ \\
Wen & M87 & Horse bone & SA98095 & -15.33 & $2540 \pm 55$ \\
or & M93 & Charcoal & SA98156 & -22.62 & $2650 \pm 50$ \\
Uncle & & Horse bone & SA98096-1 & -15.70 & $2515 \pm 55$ \\
Shang & & & SA98096-2 & -16.57 & $2595 \pm 50$ \\
\hline
\end{tabular}

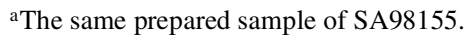

${ }^{\mathrm{b}}$ The same prepared sample of SA98094. The TO- dates were measured by ISOTRACE and were not involved in the calibration.

\section{DISCUSSION}

\section{The Boundary Constrained Empty Phases}

The calibration model should be a correct expression of the chronological process. In our study, the samples are only related with five marquises. If the model were built as:

\begin{tabular}{|c|c|}
\hline Plot & Phase "Xian"; \\
\hline\{ & Boundary "B-3"; \\
\hline Sequence "Jin Marquises" & Phase "Mu"; \\
\hline Boundary "START"; & $\begin{array}{l}\text { Bounaary B-4, } \\
\text { Phase "Wen"; }\end{array}$ \\
\hline Phase "Wu"; & Boundary “END”; \\
\hline Boundary "B-1"; & \} \\
\hline $\begin{array}{l}\text { Phase "Li"; } \\
\text { Boundary "B-2", }\end{array}$ & ; \\
\hline
\end{tabular}

this would mean that all of those phases were chronologically abutted (Bronk Ramsey 1995, 1999, 2000). This is incorrect. In fact, between Marquis $\mathrm{Wu}$ and $\mathrm{Li}$, there was Marquis Cheng. Marquises Jing and Lii should take the position between Marquis Li and Xian. To solve this problem, we put three empty phases in the relevant positions. To check the calibration result, we also set "EVENT" in the empty phases to estimate the probability of correspondence to the marquis death date. From the comparison between the historical record and the estimation result of "EVENT", we can get an auxiliary evaluation. This is also a test of the prior assumption of "Uniform Phase period" (Bronk Ramsey 1995, 1999, 2000). 


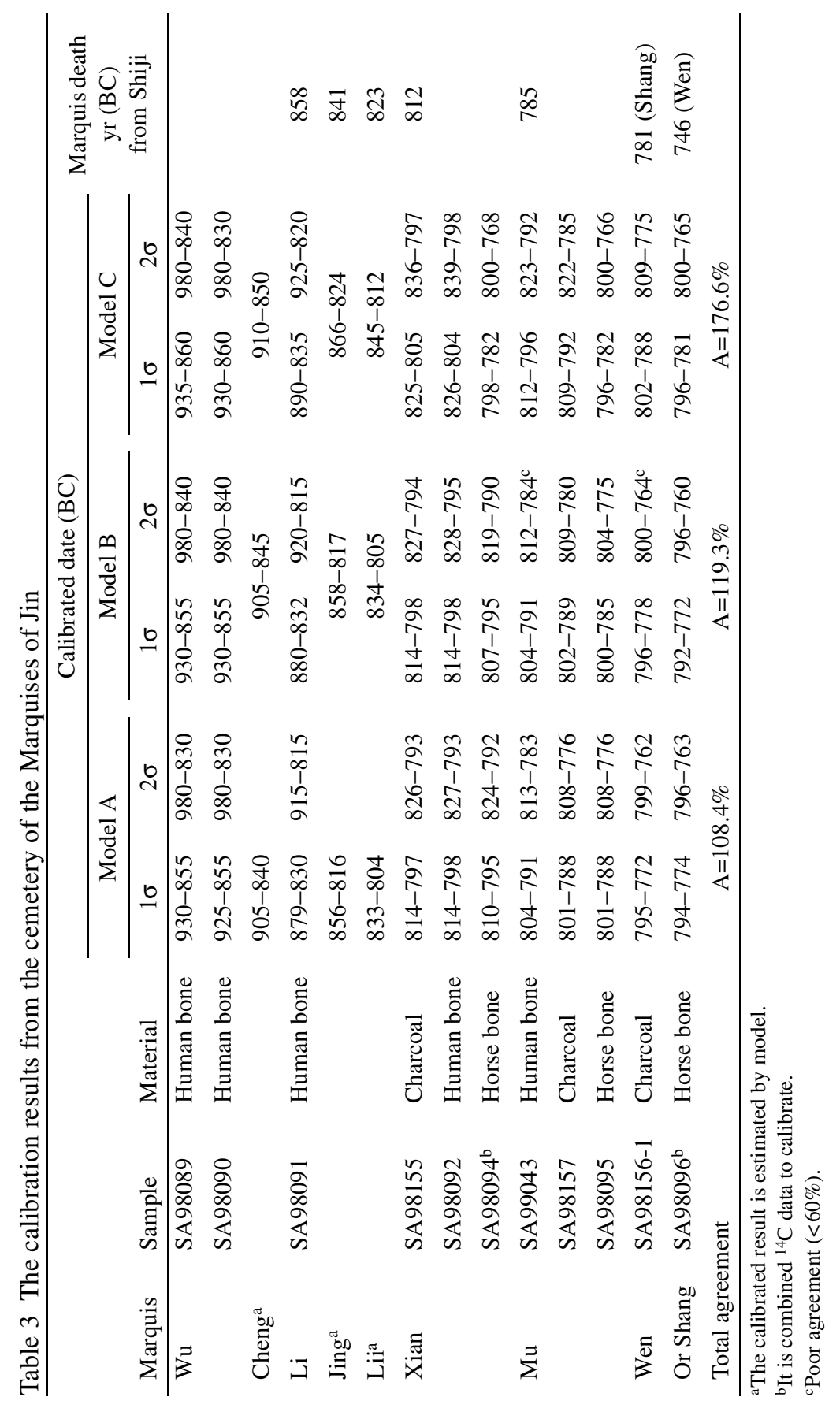


In Model C, we set a phase in which the data of M11, M87, and M93 horse bones were collected together and the phase precedes the charcoal from M93 in time sequence. Following is that part of Model C:

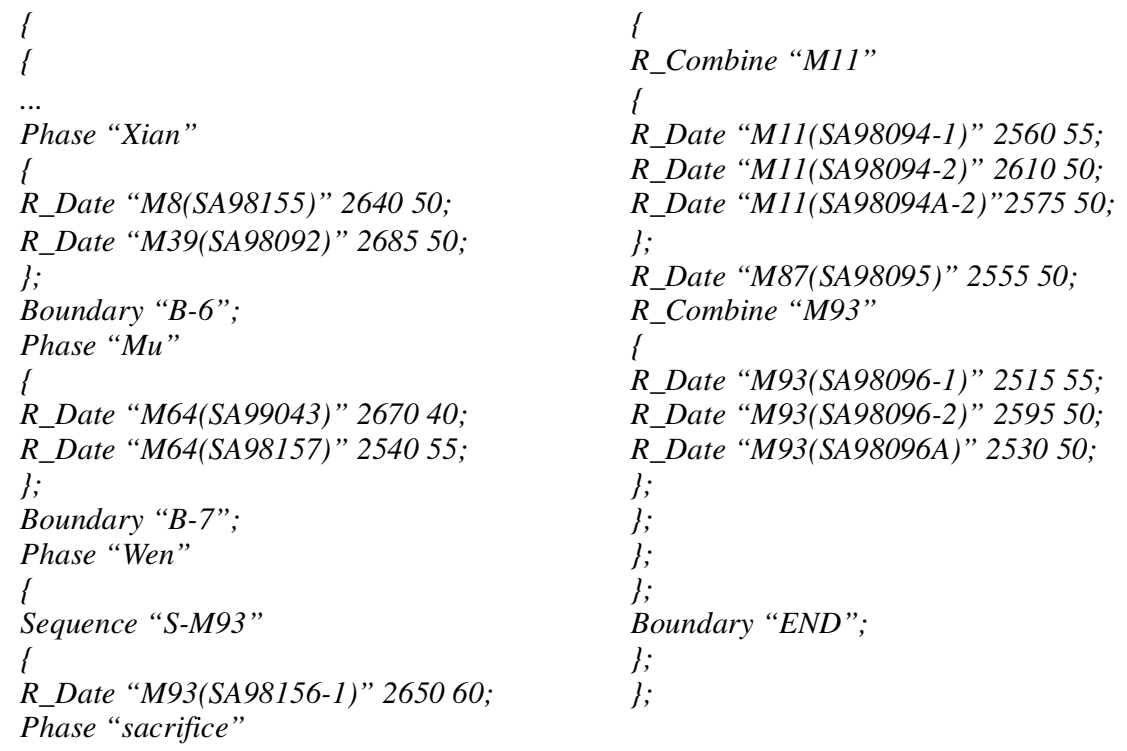

The calibration results of Models B and C are also listed in Table 3.

\section{Result Comparisons of Different Models}

From Table 3 one can see that the differences in the calibration results of those models are very small. Although Model $\mathrm{C}$ provided the oldest result, all of the results of marquises death dates agreed well with historical record of Shiji within $2 \sigma$ range. In Model B, we have ranged the sacrificial pit following the marquises tomb in time sequence, but the calibrated results of those three tombs have not been significantly changed even though the agreements of SA99043 and SA981561 were below the confidential limitation. For SA99043, the agreement was $55.8 \%$ and for SA981561, it was $59.9 \%$. The total agreement is increased from Model A to Model C. From those results, we still cannot solve the puzzle of the bury date of the sacrificial pits. Model $\mathrm{C}$ gives the oldest result and the time range is also larger, because we have moved the data of the younger samples from the earlier phases to the end of the sequence. Corresponding to the special shape of the calibration curve, the calibrated results of the samples of M8 and M64 showed very high precision. It is comparable with the precision of INTCAL98 curve. By the constraint of BOUNDARY, the result of M93 was also in a very short time range. For the possible buried time of M93, the results of all models cannot reach $746 \mathrm{BC}$. If there are only two options to select, the calibration results point toward Uncle Shang more than Marquis Wen.

\section{A Question}

In our study, the difference in the ${ }^{14} \mathrm{C}$ results of SA99043 and SA98157 is obvious. Both samples were from tomb M64. SA99043 was prepared from the human bone and SA98157 was prepared from charcoal. In general, the charcoal sample often gives an older ${ }^{14} \mathrm{C}$ age. This is a question that needs further study. 


\section{CONCLUSION}

1. In the calibration study of the cemetery of the marquises of Jin, it is necessary to use the empty phases associated with the separation by boundaries to complete the chronological sequence.

2. The calibration results agreed well with the historical record. The buried time of the sacrificial pits did not affect the calibration results significantly.

3. The estimated results of the death dates of Marquises Jing and Lii also agreed well with the historical record. That means the mathematics approach of uniform phase span of OxCal program (Bronk Ramsey 1995, 1999, 2000) is suitable in this case.

4. The calibration result of M93 indicates that the host was probably Uncle Shang instead of Marquis Wen (died in $746 \mathrm{BC}$ ).

5. Corresponding to the special segment of the calibration curve, the calibration results of the samples from M8 group, M64 group and M93 showed very high precision.

\section{ACKNOWLEDGMENT}

The authors greatly appreciate Dr Bronk Ramsey's help for the application of OxCal. We also thank Prof Li Boqian, Liu Xu, and Xu Tianjin for the supervision of archaeological information. This study was supported by National Science Foundation of China.

\section{REFERENCES}

Archaeology Dept. of Peking University and Inst. of Archaeology of Shanxi Province. 1995. Report of archaeological investigation of cemetery of Marquises of Jin. Cultural Relics 7(1995):4-39 (in Chinese).

Bronk Ramsey C. 1995. Radiocarbon calibration and analysis of stratigraphy: the OxCal program. Radiocarbon 37(2):425-30.

Bronk Ramsey C. 1999. An introduction to the use of Bayesian statistics in the interpretation of radiocarbon dates. Proceedings of the International Workshop on Frontiers in Accelerator Mass Spectrometry. Tsukuba and Sakura, Japan, 6-8 Jan 1999. p 151-60.

Bronk Ramsey C. 2000. The manual of OxCal v3.5.

Buck CE, Litton CD, Smith AFM. 1992. Calibration of radiocarbon results pertaining to related archaeological events. Journal of Archaeological Science 19:497512.

Wu X, Yuan S, Guo Z, Liu K, Lu X, Ma H, Li K, Cai L. 2000. Chronological research of cemetery of Marquises of Jin in China by AMS ${ }^{14} \mathrm{C}$ dating. Nuclear Instruments and Methods in Physics Research B. Forthcoming. 